\title{
Triangulation: Establishing the Validity of Qualitative Studies ${ }^{1}$
}

\author{
Lisa A. Guion, David C. Diehl, and Debra McDonald²
}

Validity, in qualitative research, refers to whether the findings of a study are true and certain - "true" in the sense that research findings accurately reflect the situation, and "certain" in the sense that research findings are supported by the evidence. Triangulation is a method used by qualitative researchers to check and establish validity in their studies by analyzing a research question from multiple perspectives. Patton (2002) cautions that it is a common misconception that the goal of triangulation is to arrive at consistency across data sources or approaches; in fact, such inconsistencies may be likely given the relative strengths of different approaches. In Patton's view, these inconsistencies should not be seen as weakening the evidence, but should be viewed as an opportunity to uncover deeper meaning in the data.

In this paper, five types of triangulation are presented:

1. Data triangulation

2. Investigator triangulation

3. Theory triangulation

4. Methodological triangulation

5. Environmental triangulation

\section{Data Triangulation}

Data triangulation involves using different sources of information in order to increase the validity of a study. In Extension, these sources are likely to be stakeholders in a program-participants, other researchers, program staff, other community members, and so on. In the case of an afterschool program, for example, the research process would start by identifying the stakeholder groups such as youth in the program, their parents, school teachers, and school administrators. In-depth interviews could be conducted with each of these groups to gain insight into their perspectives on program outcomes. During the analysis stage, feedback from the stakeholder groups would be compared to determine areas of agreement as well as areas of divergence.

This type of triangulation, where the researchers use different sources, is perhaps the most popular because it is the easiest to implement; data triangulation is particularly well suited for Extension given the different stakeholder groups that have vested interest in these programs.

\section{Investigator Triangulation}

Investigator triangulation involves using several different investigators in the analysis process. Typically, this manifests as an evaluation team consisting of colleagues within a field of study wherein each investigator examines

1. This document is FCS6014, one of a series of the Department of Family, Youth and Community Sciences, Florida Cooperative Extension Service, Institute of Food and Agricultural Sciences, University of Florida. Original publication date September 2002. Revised August 2011. Original written by Lisa A. Guion, former faculty member; revised by David C. Diehl and Debra McDonald. Visit the EDIS website at http://edis.ifas.ufl.edu.

2. Lisa A Guion, former faculty member; David C. Diehl, assistant professor; Debra McDonald, project coordinator; Department of Family, Youth and Community Sciences; Florida Cooperative Extension Service; Institute of Food and Agricultural Sciences; University of Florida; Gainesville, FL 32611. 
the program with the same qualitative method (interview, observation, case study, or focus groups). The findings from each evaluator would then be compared to develop a broader and deeper understanding of how the different investigators view the issue. If the findings from the different evaluators arrive at the same conclusion, then our confidence in the findings would be heightened.

For example, suppose a researcher is conducting pre- and post-observations of youth in the $4-\mathrm{H}$ public speaking program to assess changes in nonverbal communication and public speaking skills. In order to triangulate the data, it would be necessary to line up different colleagues in the same field to serve as evaluators. They would be given the same observation check sheet for pre- and post-observations, and after analysis, validity would be established for the practices and skills that were identified by each observer. While this is an effective method of establishing validity, it may not always be practical to assemble different investigators given time constraints and individual schedules.

\section{Theory Triangulation}

Theory triangulation involves the use of multiple perspectives to interpret a single set of data. Unlike investigator triangulation, this method typically entails using professionals outside of a particular field of study. One popular approach is to bring together people from different disciplines; however, individuals within disciplines may be used as long as they are in different status positions. In theory, it is believed that individuals from different disciplines or positions bring different perspectives. Therefore if each evaluator from the different disciplines interprets the information in the same way, then validity is established.

For example, suppose a researcher is interviewing participants from a nutrition program to learn what healthy lifestyle practice changes they attribute to participating in a program. To triangulate the information, a researcher could then share the transcripts with colleagues in different disciplines (i.e., nutrition, nursing, pharmacy, public health education, etc.) to see what their interpretations are. As with investigator triangulation, this method can be timeconsuming and may not be feasible in all situations.

\section{Methodological Triangulation}

Methodological triangulation involves the use of multiple qualitative and/or quantitative methods to study the program. For example, results from surveys, focus groups, and interviews could be compared to see if similar results are being found. If the conclusions from each of the methods are the same, then validity is established.

For example, suppose a researcher is conducting a case study of a Welfare-to-Work participant to document changes in her life as a result of participating in the program over a one-year period. A researcher would use interviewing, observation, document analysis, or any other feasible method to assess the changes. A researcher could also survey the participant, her family members, and case workers as a quantitative strategy. If the findings from all of the methods draw the same or similar conclusions, then validity has been established. While this method is popular, it generally requires more resources. Likewise, it requires more time to analyze the information yielded by the different methods.

\section{Environmental Triangulation}

This type of triangulation involves the use of different locations, settings, and other key factors related to the environment in which the study took place, such as the time, day, or season. The key is identifying which environmental factors, if any, might influence the information that is received during the study. These environmental factors are changed to see if the findings are the same across settings. If the findings remain the same under varying environmental conditions, then validity has been established.

For example, suppose a researcher wants to evaluate the effectiveness of a money-management program in order to determine if the program helps participants develop budgets to increase savings. If the evaluation occurs during the holiday season, there may be different results because spending is greatly increased during that time of year. In order to triangulate the data, a researcher would need to evaluate the budgeting, spending, and saving habits of participants throughout the year in order to gather true and certain information on their behavior changes. Unlike the other types of triangulation, environmental triangulation cannot be used in every case. It is only used when it is likely that the findings may be influenced by environmental factors.

\section{Advantages of Triangulation}

The benefits of triangulation include "increasing confidence in research data, creating innovative ways of understanding a phenomenon, revealing unique findings, challenging or integrating theories, and providing a clearer understanding of the problem" (Thurmond, 2001, p. 254). These benefits 
largely result from the diversity and quantity of data that can be used for analysis.

For example,

Burr (1998) used multiple triangulations to obtain a more comprehensive view of family needs in critical care. Through the use of questionnaires and selective participant interviews, this researcher found that family members who were interviewed found the sessions therapeutic, but those who were not interviewed could only communicate their frustrations on questionnaires (Thurmond, 2001, p. 254).

Thus, using interviews as well as questionnaires added a depth to the results that would not have been possible using a single-strategy study, thereby increasing the validity and utility of the findings.

\section{Disadvantages of Triangulation}

One of the primary disadvantages of triangulation is that it can be time-consuming. Collecting more data requires greater planning and organization-resources that are not always available to lead researchers (Thurmond, 2001). Other disadvantages include the "possible disharmony based on investigator biases, conflicts because of theoretical frameworks, and lack of understanding about why triangulation strategies were used" (Thurmond, 2001, p. 256).

\section{Conclusion}

Quite simply, triangulation is a useful tool to use in qualitative research, but one should weigh the advantages and disadvantages before application in Extension work. If researchers decide that triangulation is desired, there are several types of triangulation that can be used: data, investigator, theory, methodological, and environmental. Triangulation can be used to deepen the researchers' understanding of the issues and maximize their confidence in the findings of qualitative studies.

\section{Further Reading}

Golafshani, N. (2003). Understanding reliability and validity in qualitative research. The Qualitative Report, 8(4), 597-607. http://www.nova.edu/ssss/QR/QR8-4/golafshani. pdf

Olsen, W. (2004). Triangulation in social research: Qualitative and quantitative methods can really be mixed. http:// www.ccsr.ac.uk/staff/Triangulation.pdf
Merriam, S. B. (2009). Qualitative Research: A Guide to Design and Implementation. San Francisco, CA: John Wiley \& Sons.

Stake, R.E. (2010). Qualitative Research: Studying How Things Work. New York, NY: Guilford Press.

\section{References}

Burr, G. (1998). Contextualizing critical care family needs through triangulation: An Australian study. Intensive \& Critical Care Nursing, 14(4), 161-169.

Patton, M.Q. (2002). Qualitative Research and Evaluation Methods. Thousand Oaks, CA: Sage Publications.

Thurmond, V. (2001). The point of triangulation. Journal of Nursing Scholarship, 33(3), 254-256. Retrieved from: http:// www.ruralhealth.utas.edu.au/gr/resources/docs/the-pointof-triangulation.pdf. 